\title{
Were our leaders ready to implement the changes? - a case study
}

\author{
Malgorzata Jasiulewicz-Kaczmarek ${ }^{1,}$, Katarzyna Szwedzka ${ }^{2}$ \\ 1,2Poznan University of Technology, Poznan, Poland \\ ${ }^{2}$ Full address of second author, including country \\ *email malgorzata.jasiulewicz-kaczmarek@put.poznan.pl
}

\begin{abstract}
The goal of the paper is to introduce results of the research carried in a large industrial company and concerning leadership style assessment. The results of the research presented in the paper refer to the specific period for the company analyzed, as it went through a kind of revolution. Over the last year the company was a subject of reorganization, extensive organizational changes were implemented throughout all its functional areas. The executives wanted to get the feedback information on how department managers implement changes in the areas they are in control of.
\end{abstract}

Keywords: leader, leadership, organizational change

\section{Introduction}

Organizational change is a constant element that affects all organizations [1]. The important element for a successful change in any organization is "Leadership". Northouse (2010) defines leadership as "a process whereby an individual influences a group of individuals to achieve a common goal" [2]. Leadership is a dynamic process in which the leader and followers interact in such a way as to generate change in the organization (leadership is change focus). Organizational leadership has a direct influence on behavior in the work environment that enables change and innovative thinking and actions $[3,4,5]$ that overcome individual resistance and obstacles. People are inherently resistant to change; avoiding or resisting it is human nature [6]. There are known various methods to remedy it [7] Thus the importance of the leader's role and skills in driving change is clear.

The goal of the paper is introducing results of the research carried in a large industrial company and concerning leadership style measurement. The company analyzed carries such a research in regular basis, every year. The general goal of the research on leadership style in the company is to recognize opinions of employees on management style and including the employees in the management process. The executives assume that managers should build an atmosphere of trust and encourage employees to open dialogue. The results of the research presented in the paper refer to the period crucial for the company. Over the last reorganization of the company, was carried and major organizational changes to its scope covered all functional areas of the company were introduced. Thus, the specific goal of the research for the executives was to receive feedback on how the managers implemented changes to various areas of the company.

\section{Methodology of assessment of leadership style implemented in the company}

The assessment methodology implemented in the company is composed of four stages, which are repeated regularly at yearly intervals.

Step 1. Preparation of leaders for the assessment. During this stage the leaders are informed on assessment methods and analysis of their leadership style. In the first step, the leader should answer the question (Fig. 1): What do I expect as a leader?

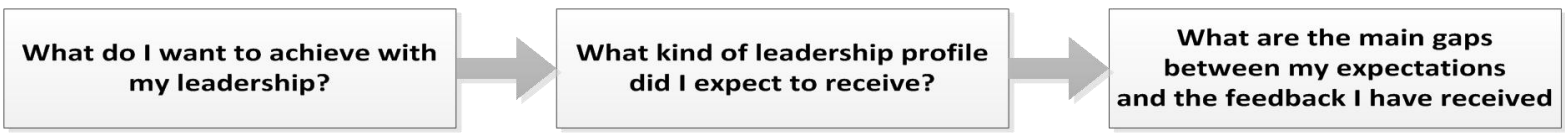

Fig. 1 The first step of analysis of individual leadership style 
In the second step the leader should answer some further questions, i.e.: What leadership style do I represent? Leaders need to set their priorities from the perspective of what's important for the business, the development of their team and their own growth (Fig.2).

\begin{tabular}{|c|c|}
\hline My team & Business oBjectives \& Assignment \\
\hline $\begin{array}{l}\text { What leadership is important to the co-workers } \\
\text { in my team? What are the experiences } \\
\text { and values of my co-workers? }\end{array}$ & $\begin{array}{l}\text { What qualities are important for } \\
\text { my business situation? }\end{array}$ \\
\hline $\begin{array}{l}\text { What support do I need in my } \\
\text { development? }\end{array}$ & $\begin{array}{l}\text { What motivates my in my role } \\
\text { as leader? What part of leadership } \\
\text { do I find difficult/easy? }\end{array}$ \\
\hline Support & Who I am as a person $\&$ own skills \\
\hline
\end{tabular}

Fig. 2 The second step of of analsis of individual leadership style

Step 2. Preparation of employees to assessment. As a part of this step, the meetings with employees are carried, during which the goal of the research is presented, the questions included in the survey are explained, and the evaluation routine is introduced. The survey is composed of 5 parts (Table 1) "My leader ...: Lead and develop people (part A), Inspire and clarify (part B) Create togetherness (part C), Find better ways (part D) Enable change ( part E) ". Depending on the goal defined by the managers, questions included in each part of the survey are modified.

Tabela 1 Criteria for assessing leaders

\begin{tabular}{|c|c|c|}
\hline & My leader.... & \\
\hline A & $\begin{array}{l}\text { Lead and develop } \\
\text { people }\end{array}$ & $\begin{array}{l}\text { A1 ...gives me constructive feedback on my work performance } \\
\text { A2 ...delegates responsibilities that challenge me and allow me to grow } \\
\text { A3 ...challenges and supports me to find solutions and to make my own decisions } \\
\text { A4 ...helps me recognise opportunities for learning in my daily work }\end{array}$ \\
\hline B & Inspire and clarify & $\begin{array}{l}\text { B1 ...communicates the company vision in an inspiring way } \\
\text { B2 ...communicates in an open and straightforward way } \\
\text { B3 ...listens to my opinions, thoughts and ideas }\end{array}$ \\
\hline $\mathrm{C}$ & Create togetherness & $\begin{array}{l}\text { C1 ... actively seeks input from people with diverse backgrounds, views and approaches } \\
\text { C2 ... builds trustful relationships at work } \\
\text { C3 ...develops collaboration with people outside our team to optimise results }\end{array}$ \\
\hline $\mathrm{D}$ & Find better ways & $\begin{array}{l}\text { D1 ...encourages me to challenge the common ways and to seek improvement } \\
\text { D2 ... actively looks for opportunities to simplify the way we work }\end{array}$ \\
\hline $\mathrm{E}$ & Enable change & $\begin{array}{l}\text { E1 ...helps me understand the reasons behind changes that affect me } \\
\text { E2 ...continuously communicates progress of the changes that affect me } \\
\text { E3 ...supports me in my work, when change and new ways are introduced }\end{array}$ \\
\hline
\end{tabular}

Each of the elements of the survey $(\mathrm{A} 1, \mathrm{~A} 2, \ldots, \mathrm{E} 3)$ is evaluated with the scale of a 5 -levels, where the 5 and 4 ratings are positive 3 -is neutral 2 and 1 is negative. The company implemented the principle according to which the leadership profile is strong, if the rating obtained for the element assessed is not lower than $75 \%$, it is good when the assessment ranges from $60 \%$ to $74 \%$, and when the result of the research is lower than $60 \%$ the element this is a weak point and requires decisive improvement activities.

Step 3. Conducting a survey among employees. The actual survey is conducted for a month. Such a long period of time allows all employees to participate in the assessment. The research is conducted in all areas of the company, both production and support (eg. maintenance department), trade and administration. After the assessment, the results are counted by a team selected from among employees.

Step 4: Transfer the feedback to managers and organize meetings with the team to discuss the survey results. The leaders wanting to develop and identify themselves with the vision of the company, after recognizing the opinion of the team, should answer the three questions: What should I start doing? What should I stop doing? What should I continue doing? 


\section{Results and discussion}

The results of the research presented in the following chapter refer to the period crucial for the company. Over the last year was the company was re-organized, and major organizational changes to its scope covering all functional areas of the company were introduced. The goal of the study was to receive feedback from the managers on how to make changes to various areas of the company. Due to further changes planned by the company management, the opinion of the employees was especially important. The survey was conducted in all the production departments in the maintenance department and in the department of trade and administration. This paper presents the research results obtained in the two production departments referred to as A and B. The research was conducted among workers at all shifts (there is the four-shifts work system implemented in the company). The results of the survey (presented in the Table 1) for departments A and B are shown in the Figures 3 and 4 respectively.

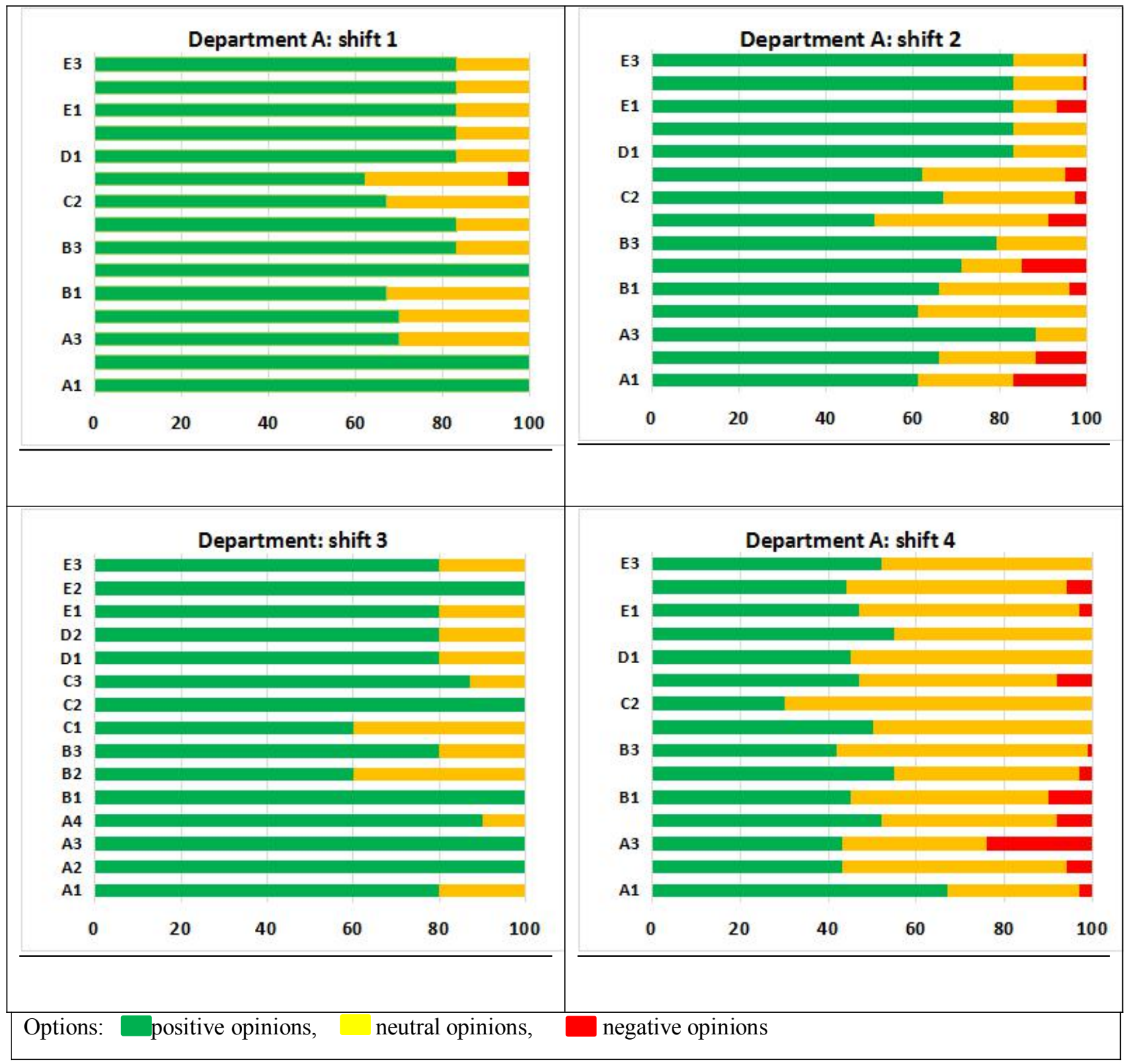

Fig. 3 Result oft he aassessment of leadership carried in the department A 


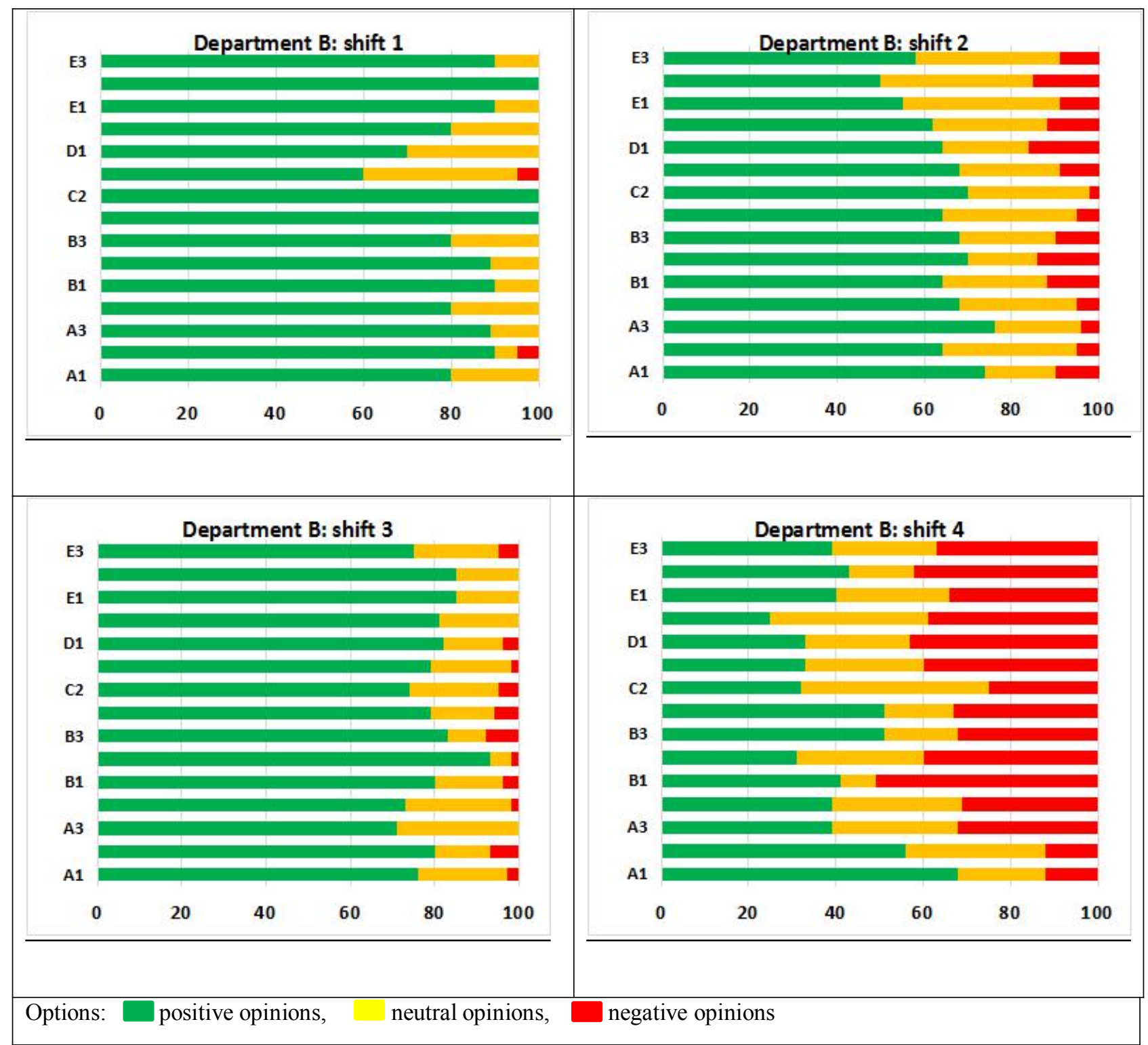

Fig. 4 Results of the assessment of leadership carried in the Department B

The research conducted indicated which of the leaders should change their attitude to the teams they lead, and which of the leaders should be a row model providing a good practice. The leaders of the departments in which the rating was the lowest (below 60\%), should examine in detail the research results, to consider the way they managed the teams when implementing changes and answer the three key questions: What should I start doing? What should I stop doing? What should I continue doing? and based on the answers start the process of self-improvement of their own leadership style. A summary rating of how the leaders implemented changes in the A and B departments and the level of employee satisfaction with the leaders who were the drivers of the changes is presented in the figure 5.

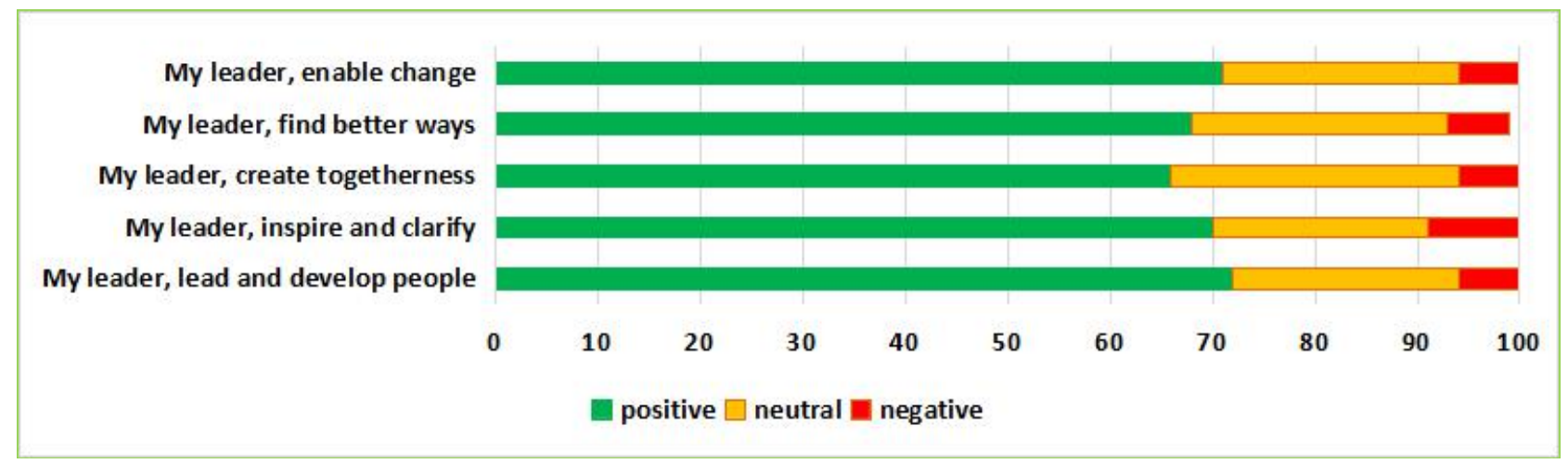


Fig.5. General assessment of leaders of A and B department according to company's employees

According to the scale of assessment of the profile of leadership implemented in the company the score in each of the analyzed criteria was higher than $60 \%$, so, it can be concluded that it is on a good level. From managers of the company point of view, this information is beneficial. However, detailed analysis of assessment of individual leaders and the areas of evaluation shows that there are also weak points (rated below 60\%). Therefore, according to the authors the further changes planned for the company should be delayed as the company is not ready for it. If the further change is to support the objectives of the organization, the former must be recognized as durable, and it is associated among others with building and promoting good relations between the leader and the team.

\section{Conclusion}

In many organizations, most of the initiatives for changes fail because at the planning stage real problems and obstacles that are possibly encountered, are not considered $[8,9]$. The important role of a leader whose task is to build the right relationships and trust to the developed improving actions is not considered either. The trust that people have for their leader often reflects employee satisfaction with the actions taken by the company, and improves team productivity and encourages healthy competition between them.

\section{References}

[1] S. Saniuk, A. Samolejova, A. Saniuk and R. Lenort: Metalurgija, Vol. 54 (2015), pp. 567-570.

[2] P.G. Northouse, (2010). Leadership: Theory and practice (5th ed). Thousand Oaks, CA: SAGE Publications

[3] Gilley, The manager as change leader. Westport, CT: Praeger (2005).

[4] Michaelis, R. Stegmaier and R. Sonntag: Journal of Change Management, Vol. 9 (2009), pp.399-417

[5] M. Higgs and D. Rowland: Journal of Applied Behavioral Science Vol. 47 (2011) pp. 309-335

[6] W. H. Bovey and A. Hede: Journal of Managerial Psychology, Vol. 16 (2001), pp. 534-549.

[7] L Pacholski and A. Jasiak: Advances in Industrial Ergonomics and Safety IV, pp. 27-33, Taylor \& Francis LTD, 1992.

[8] J. P., Kotter: Leading Change. Harvard Business Review, January (2007), pp. 92-107

[9] J. Harasymiuk, M. Ciak, B. Ferek, A. Rudziński, J. Tyburski and A. Korona: Technical Sciences, (2016), 19(1), pp. 27-39 